\title{
Enrichment of the Glycyrrhizic Acid from Licorice Roots (Glycyrrhiza glabra L.) by Isoelectric Focused Adsorptive Bubble Chromatography
}

\author{
Eyyüp Karaoğul, ${ }^{1}$ Perihan Parlar, ${ }^{2}$ Harun Parlar, ${ }^{3}$ and M. Hakkı Alma1 \\ ${ }^{1}$ Department of Forest Industry Engineering, Faculty of Forestry, Kahramanmaraş Sutcu Imam University, Kahramanmaraş, Turkey \\ ${ }^{2}$ Faculty of Health Sciences, Istanbul Esenyurt University, Esenyurt, 34510 Istanbul, Turkey \\ ${ }^{3}$ Department of Chemical-Technical Analysis and Chemical Food Technology, Technical University of Munich, Munich, Germany \\ Correspondence should be addressed to Eyyüp Karaoğul; e.karaogul@hotmail.com
}

Received 28 October 2015; Revised 16 December 2015; Accepted 17 December 2015

Academic Editor: Hassan Y. Aboul Enein

Copyright (C) 2016 Eyyüp Karaoğul et al. This is an open access article distributed under the Creative Commons Attribution License, which permits unrestricted use, distribution, and reproduction in any medium, provided the original work is properly cited.

\begin{abstract}
The main aim of this study was to enrich glycyrrhizic acid ammonium salt known as one of the main compounds of licorice roots (Glycyrrhiza glabra L.) by isoelectric focused adsorptive bubble separation technique with different foaming agents. In the experiments, four bubble separation parameters were used with $\beta$-lactoglobulin, albumin bovine, and starch (soluble) preferred as foaming agents and without additives. The enrichment of glycyrrhizic acid ammonium salt into the foam was influenced by different additive substances. The results showed that highest enrichment values were obtained from $\beta$-lactoglobulin as much as 368.3 times. The lowest enrichment values (5.9 times) were determined for the application without additive. After enrichment, each experiment of glycyrrhizic acid ammonium salt confirmed that these substances could be quantitatively enriched into the collection vessel with isoelectric focused adsorptive bubble separation technique. The transfer of glycyrrhizic acid ammonium salt into the foam from standard solution in the presence of additive was more efficient than aqueous licorice extract.
\end{abstract}

\section{Introduction}

Glycyrrhiza glabra L. (licorice) is a ligneous perennial shrub growing in Mediterranean region and Asia and widespread in Turkey, Italy, Spain, Russia, Syria, Iran, China, and Israel [1]. The licorice having multi years has blue and violet flowers [2].

Licorice is a favorable herb used in food and pharmaceutical for thousands of years in the traditional medicine system. The secondary metabolites of this plant have long been evaluated for their use in relieving respiratory ailments (such as bronchitis, allergies, cold, tuberculosis, and sore throats), their demulcent effect (soothing, coating agent), relieving stomach burn symptoms including heartburn resulting from reflux or any other cause, and treating gastritis, inflammatory disorders, liver problems, and skin diseases [3]. The licorice roots have antiulcer, expectorant, diuretic, laxative, sedative [4], antipyretic [5], antimicrobial, anti-inflammatory [6], antioxidant, and significant antitumor activity [7], memory enhancement effect [8], and anxiolytic activities [9].
Moreover, skin whitening [10], skin depigmenting [11], antiaging and antierythemic [12] activities, an emollient [13], an antiacne [14] activity, a potential cancer chemopreventive agent [15], cardioprotective effects [16], restoring liver function in patients suffering from hepatitis C [17], antidepression [18], hepato protective [19], and atherosclerosis [20] and photoprotection effects [21] could be mainly provided by using licorice extract.

The medicinal and pharmacological uses of licorice ingredients have been described in several studies [22-24]. Licorice contains a variety of substances such as sugars up to $18 \%$, flavonoids, saponoids, amino acids, sterols, gums, and starch. The effective ingredient in licorice is mainly glycyrrhizin, which has antiviral, anti-inflammatory [6] and antioxidant properties [25] and a triterpenoid glycoside, which constitutes up to $14 \%$ of total soluble solids content [26] giving the characteristic sweet taste from the licorice root. Glycyrrhizin has few calories and can be used in the form of ammonium glycyrrhizin or monoammonium glycyrrhizin in 
nutrients. There are a lot of efficacious compounds in licorice roots like licochalcone known as a novel estrogenic flavonoid isolated from herb licorice root that was reported to show significant antitumor activity in various malignant human cell lines [7].

The licorice root extract has been widely used in the nutriment industry as a sweetening agent as ammonium glycyrrhizin is about 50 times as sweet as cane sugar [27]. There is a growing commercial interest in using licorice root extract in food foams. Foaming properties of licorice extract influence the sensory quality and shelf-life of the final product [28]. So, the licorice has found widespread usage as a foaming agent in beverages [29], in halva and sweets [30,31]. Commercially, the licorice root extract is supplied in concentrated or powdered form for the ease of transportation [26].

Biologically active separation of natural products from useful plants or medicinal herbs is of great interest to the pharmaceutical and food industries. The separation techniques known as solvent extraction or supercritical fluid extraction are usually employed for isolation of valuable ingredients. Because of the ecosystem harm of organic solvents used, an alternative method of general interest is foam fractionation called a method based on adsorptive bubble separation technique. For the enrichment of surface active substances, gases (e.g., nitrogen, oxygen, air, and carbon dioxide) are introduced. So, enrichment was formed into the foam [32]. The separation technique for biological effective compounds of foam fractionation by adsorptive bubble chromatograph is more effective, especially at low initial concentrations (up to $1 \times 10^{10} \mathrm{~mol} / \mathrm{L}$ ) of substances [3236]. It is suitable method for the quantitative and effective enrichments in comparison with other traditional methods mentioned above [37]. No study has been done about enrichment of chemical composition from Glycyrrhiza glabra roots with bubble separation techniques so far. So, the objective of this study was to enrich the biological effective fractions by adsorptive bubble separation technique.

\section{Experimental}

2.1. Solution and Reagents. The chemical solvents used were of spectroquality grade for HPLC and analytical grade. All of the chemical solvents were obtained from Sigma Chemicals Co. such as glycyrrhizic acid ammonium salt as HPLC standard and $\beta$-lactoglobulin, albumin bovine, and starch (soluble) as foaming agents. The water used in experiments was purified using Milli-Q System (Millipore Corp.). Glycyrrhiza glabra L. roots were purchased from a local market.

2.2. Preparation and Extraction of Licorice. The licorice powder $(10 \mathrm{~g})$ was mixed with $300 \mathrm{~mL}$ distilled water. Mixtures were heated to $60^{\circ} \mathrm{C}$ under stirring for $4 \mathrm{~h}$ and, after cooling down, the solution was filtered by using a fluted filter. Finally, the licorice extract was stored in the refrigerator at $4^{\circ} \mathrm{C}$ until the absorptive bubble separation.

2.3. Adsorptive Bubble Chromatograph with Different Additional Substance. As shown in Figure 1, the equipment was

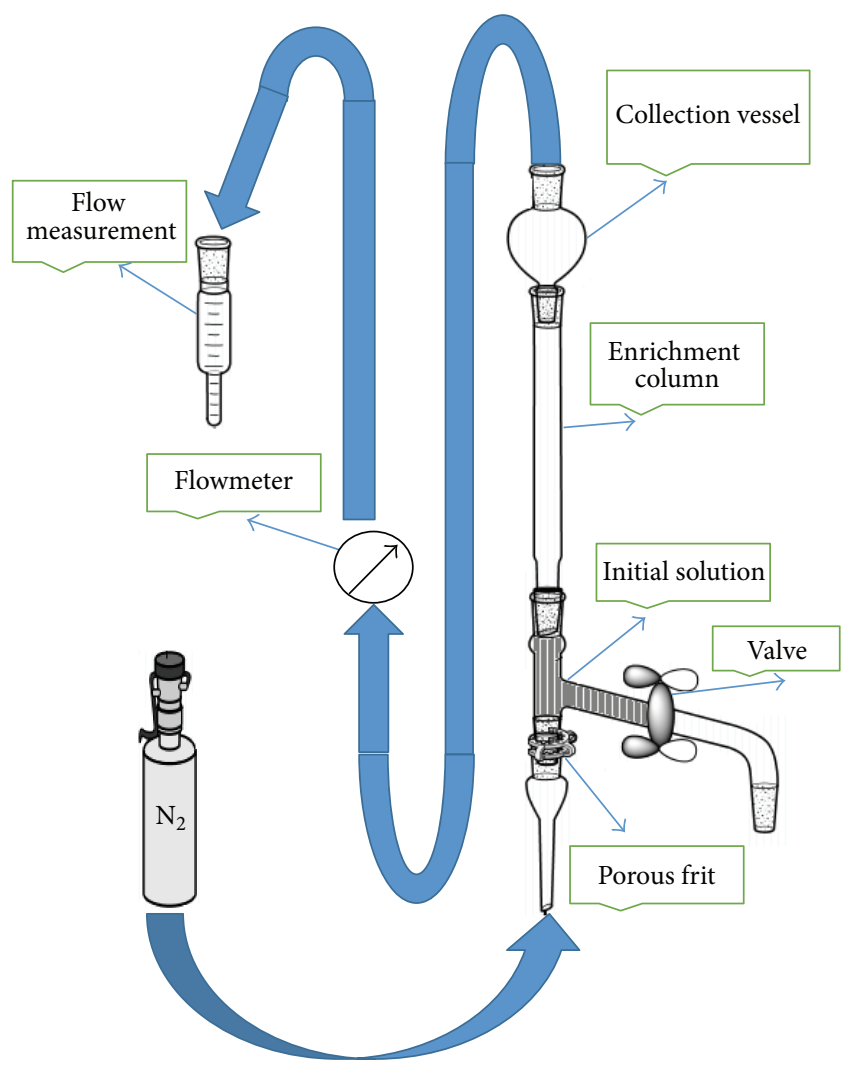

FIgURE 1: Scheme of the Adsorptive Bubble Separation Apparatus.

established with a glass column (ID $18.5 \mathrm{~mm}$, length $15 \mathrm{~cm}$ ) with a porous frit (P 3, porosity $16-40 \mu \mathrm{m})$, flask $(250 \mathrm{~mL})$, initial solution column (ID $18.5 \mathrm{~mm}$, length $15 \mathrm{~cm}$ ), and volumetric flask (for flow measurement $\mathrm{mL} / \mathrm{min}$ ). The attention was taken that the column was highly clean and that the ground glass was free of fat. Gas bubbles were created by passing a stream of nitrogen through a glass frit dipping into the liquid pool at the bottom of the column. The bubble rises up the column and the liquid part of the bubble drains due to gravitation back to the initial solution. In order to increase the foaming ratio, the foaming agents such as $\beta$-lactoglobulin, albumin bovine, and starch (soluble) were used in this study. The foam was collected in collection vessel at the upper part of apparatus. After bubble separation, enrichment samples collected in collection vessel were weighed. The separation takes place by means of an optional adsorption at the liquid gas interface of raised bubbles.

In the experiments, four bubble separation parameters were used with $\beta$-lactoglobulin, albumin bovine, and starch (soluble) preferred as foaming agents and without additive. For each experiment, $70 \mathrm{~mL}$ of licorice root extraction amount was prepared, containing $30 \mathrm{mg}$ foaming agents in 120 min foaming time. The carrier gas was nitrogen with a flow rate of $30 \mathrm{~mL} / \mathrm{min}$. The $\mathrm{pH}$ value was also 2.5 . The enrichment ratios $(E)$ were calculated as follows:

$$
E=\frac{C_{\text {foam }}}{C_{\text {Start }}},
$$


TABLE 1: Regression equation, retention time, and correlation coefficient of reference compounds on HPLC.

\begin{tabular}{lcccc}
\hline Number & $\begin{array}{c}\text { Sample concentrations } \\
(\mathrm{mg} / \mathrm{L})(\mathrm{ppm})\end{array}$ & Retention time $(\mathrm{min})$ & Regression equation $^{\mathrm{a}}$ & ${\text { Correlation coefficient }\left(r^{2}\right)}$ \\
\hline$(1)$ & 138 & & & \\
$(2)$ & 207 & 3.04 & $y=0.0016 x-21.842$ & 0.9917 \\
$(3)$ & 276 & & & \\
$(4)$ & 355 & & & \\
\hline
\end{tabular}

${ }^{\mathrm{a}} x$ : peak area of components, $y$ : concentration of components.

TABLE 2: Correlation coefficient, enrichment addition, type, and volume of all the sample types on HPLC.

\begin{tabular}{|c|c|c|c|c|c|}
\hline Number & $\begin{array}{l}\text { Enrichment } \\
\text { addition }\end{array}$ & Sample type & Sample volume $(\mu \mathrm{L})$ & $\begin{array}{l}\text { Distilled water volume } \\
\qquad(\mu \mathrm{L})\end{array}$ & $\begin{array}{c}\text { Correlation } \\
\text { coefficient } \\
\left(r^{2}\right)\end{array}$ \\
\hline (1) & \multirow{2}{*}{$\beta$-Lactoglobulin } & Start extract & 25,50 , and 100 & 975,950 , and 900 & 0.9941 \\
\hline$(2)$ & & Extract foamed & 300,500 , and 1000 & 700,500 , and 0 & 0.9978 \\
\hline (1) & \multirow{2}{*}{ Albumin bovine } & Start extract & 25,50 , and 100 & 975,950 , and 900 & 0.9943 \\
\hline$(2)$ & & Extract foamed & 300,500, and 1000 & 700,500 , and 0 & 0.9996 \\
\hline (1) & \multirow{2}{*}{ Starch (soluble) } & Start extract & 25,50 , and 100 & 975,950 , and 900 & 0.9949 \\
\hline$(2)$ & & Extract foamed & 300,500 , and 1000 & 700,500 , and 0 & 0.9978 \\
\hline (1) & \multirow{2}{*}{ Without additive } & Start extract & 25,50 , and 100 & 975,950 , and 900 & 0.9951 \\
\hline (2) & & Extract foamed & 300,500 , and 1000 & 700,500 , and 0 & 0.9998 \\
\hline
\end{tabular}

where $E$ is enrichment ratio, $C_{\text {foam }}$ is concentration $(\mu \mathrm{g} / \mathrm{mL})$ of foaming after enrichment with bubble separation, and $C_{\text {start }}$ is initial concentration as $\mu \mathrm{g} / \mathrm{mL}$. The eluting fractions were collected at fixed intervals and after foam destruction with $1 \mathrm{~mL}$ eluent $(A)$, used in HPLC as mobile phase subjected directly to analysis.

All the calibration curves were plotted based on linear regression analysis of the integrated peak areas $(x)$ versus concentrations $(y, \mathrm{mg} / \mathrm{L}, \mathrm{ppm})$ of the reference solution at four different concentrations. Regression equation, retention time, correlation coefficient, and standard curve of glycyrrhizic acid ammonium salt in HPLC were shown in Table 1 and Figure 2.

The starting, remaining solution and extract foamed samples were analyzed by HPLC for identification and quantification of glycyrrhizic acid ammonium salt.

As shown in Table 2, the correlation coefficients for all extracts were plotted based on linear regression analysis of the integrated absorbance value $(x)$ versus concentrations $(y$, $\mathrm{mg} / \mathrm{mL}$ ) of the reference solution at four different concentrations. As seen in correlation coefficients, the calibration curves plotted in the different concentration were on the linear for all the experiment and the results showed that the extract has small standard deviation.

2.4. HPLC Study. The HPLC analysis was performed on Gynkotek 480 equipped with Rheodyne 8125 injector and $20 \mu \mathrm{L}$ sample loop, a Gynkotek UV-detector (UVD $340 \mathrm{~s}$; wavelength was selected as $254 \mathrm{~nm}$ ), Kromasil $100 \mathrm{C} 18$ columns (Knauer, Germany: $5 \mu \mathrm{m}, 25064.6 \mathrm{~mm}$, column temperature $258^{\circ} \mathrm{C}$ ), and Uniflow Degasser DG-1310. The eluent contained $210 \mathrm{~mL}$ of methanol, $210 \mathrm{~mL}$ of acetonitrile,

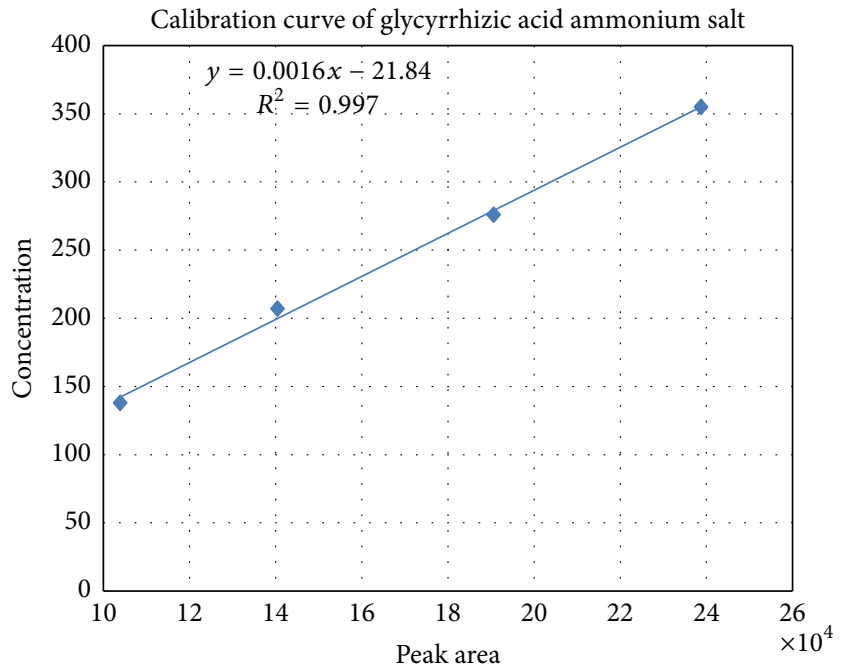

FIGURE 2: Standard curve of reference compounds on HPLC.

$174 \mathrm{~mL}$ of distillated water, and $6 \mathrm{~mL}$ glacial acetic acid without gradient elution, at a flow rate of $1 \mathrm{~mL} \mathrm{~min}^{-1}$.

\section{Results and Discussion}

The licorice root extracts gave plentiful foam during bubble separation, when $\beta$-lactoglobulin, albumin bovine, and starch (soluble) (30 mg for each experiment) were used as foaming addition in licorice extract. The foam without addition of a surface active substance was weak in the licorice extract. This situation was probably due primarily to the reduction of surface tension. 
TABLE 3: Enrichment ratios and start, foam, and residual extract concentrations ( $\mathrm{mg} / \mathrm{mL}$ ) of Glycyrrhiza glabra with $\beta$-lactoglobulin, albumin bovine, and starch (soluble) preferred as foaming agents and without additive.

\begin{tabular}{|c|c|c|c|c|}
\hline $\begin{array}{l}\text { Experiment } \\
\text { number }\end{array}$ & $\begin{array}{c}\text { Foaming agent } \\
\text { method (mg) }\end{array}$ & $\begin{array}{c}\text { Initial concentration } \\
(\mu \mathrm{g} / \mathrm{mL})\end{array}$ & $\begin{array}{c}\text { Foam concentration } \\
(\mu \mathrm{g} / \mathrm{mL})\end{array}$ & Enrichment ratio (ER) \\
\hline 1 & $\beta$-Lactoglobulin & $12 \pm 0.986$ & $4420 \pm 183.43$ & 368.3 \\
\hline 2 & Albumin bovine & $24 \pm 1.982$ & $2170 \pm 90.055$ & 90.4 \\
\hline 3 & Starch (soluble) & $348 \pm 29.884$ & $3260 \pm 135.29$ & 9.4 \\
\hline 4 & Without additive & $360 \pm 33.88$ & $2100 \pm 87.15$ & 5.9 \\
\hline
\end{tabular}

The licorice root extraction amount, $\mathrm{pH}$ value, foaming agent amount, foaming time, and gas flow rate were taken as optimum on the enrichment. The foaming agent type was used as variable, while other parameters were stable. The results given in Table 3 illustrate that the higher or lower enrichment rates of glycyrrhizic acid ammonium salt into the foam fraction from licorice extract can be observed during all experiments. Varying the additional substances influenced the enrichment ratios and yields.

As clearly shown in Table 3, the foam separated licorice extract treated with $\beta$-lactoglobulin has the highest enrichment ratio of glycyrrhizic acid ammonium salt. Moreover, the enrichment ratio of the glycyrrhizic acid ammonium salt from licorice extract treated with $\beta$-lactoglobulin is as much as 368,3 times higher compared to that of initial concentration. The lowest enrichment ratios were determined from the separation without additive as much as 5,9 times lower than that of initial concentration. Besides, no significant difference in the enrichment ratio is determined between bubbling processes with soluble starch and without any foaming agent. About 62 and 16 times' increments are recorded due to addition of $\beta$-lactoglobulin and albumin bovine used for foaming, respectively. The $\beta$-lactoglobulin method finds highest enrichment ratio for glycyrrhizic acid ammonium salt and may be preferred as enrichment method in the bubble separation techniques in industry because of the highest yield.

\section{Conclusions}

The glycyrrhizic acid ammonium salt was successfully enriched by Glycyrrhiza glabra L. root extract quantitatively by isoelectric focused adsorptive bubble separation technique with and without foaming agents. The findings showed that $\beta$-lactoglobulin used as a foaming agent has the highest enrichment ratio of glycyrrhizic acid ammonium salt compared to initial concentration and other foaming agents on the adsorptive bubble separation technique. The bubbling process without any foaming agent was substantially observed to have the lowest enrichment ratio compared to the ones with foaming agents such as beta-lactoglobulin, albumin bovine, and starch (soluble). Besides, the bubble separation enrichments with and without starch used for foaming did not give any significant difference. Therefore, transfer of effective compound to the foam from solution in the presence of $\beta$-lactoglobulin and albumin bovine was more efficient compared to that of aqueous licorice extract.

\section{Conflict of Interests}

The authors declare that there is no conflict of interests regarding the publication of this paper.

\section{References}

[1] Y. Asada, W. Li, and T. Yoshikawa, "Biosynthesis of the dimethylallyl moiety of glabrol in Glycyrrhiza glabra hairy root cultures via a non-mevalonate pathway," Phytochemistry, vol. 55, no. 4, pp. 323-326, 2000.

[2] G. deMastro, G. Circella, G. deMastro, D. Palevitch, and E. Putievsky, "Effect of soil depth and cropping length on the root system growth in liquorice (Glycrrhiza glabra L.)," in Proceedings of the International Symposium on Medicinal and Aromatic Plants, vol. 344, pp. 518-522, International Society for Horticultural Science (ISHS), Leuven, Belgium, November 1993.

[3] H. Xu, D. S. Fabricant, C. E. Piersen et al., "A preliminary RAPDPCR analysis of Cimicifuga species and other botanicals used for women's health," Phytomedicine, vol. 9, no. 8, pp. 757-762, 2002.

[4] H. Hikino, "Recent research on oriental medicinal plants," in Economic and Medicinal Plant Research, H. Wagner, H. Hikino, and N. R. Farnsworth, Eds., p. 53, Academic Press, London, UK, 1985.

[5] S. Lata, R. S. Saxena, A. Kumar, S. Kakkar, V. K. Srivastava, and K. K. Saxena, "Comparative antipyretic activity of Ocimum sanctum, Glycyrrhiza glabra and aspirin in experimentallyinduced pyrexia in rats," Indian Journal of Pharmacology, vol. 31, no. 1, pp. 71-75, 1999.

[6] T. Yokota, H. Nishio, Y. Kubota, and M. Mizoguchi, "The inhibitory effect of glabridin from licorice extracts on melanogenesis and inflammation," Pigment Cell Research, vol. 11, no. 6, pp. 355-361, 1998.

[7] Y. Fu, T.-C. Hsieh, J. Guo et al., "Licochalcone-A, a novel flavonoid isolated from licorice root (Glycyrrhiza glabra), causes G2 and late-G1 arrests in androgen-independent PC-3 prostate cancer cells," Biochemical and Biophysical Research Communications, vol. 322, no. 1, pp. 263-270, 2004.

[8] D. Dhingra, M. Parle, and S. K. Kulkarni, "Memory enhancing activity of Glycyrrhiza glabra in mice," Journal of Ethnopharmacology, vol. 91, no. 2-3, pp. 361-362, 2004.

[9] S. D. Ambawade, V. S. Kasture, and S. B. Kasture, "Anxiolytic activity of Glycyrrhiza glabra Linn," Journal of Natural Remedies, vol. 2, pp. 130-134, 2001.

[10] K. T. Lee, B. J. Kim, J. H. Korea, and M. Heo, "Biological screening of 100 plant extracts for cosmetic use (I): inhibitory activities of tyrosinase and DOPA auto-oxidation," in Proceedings of the 19th IFSCC Congress, Sydney, Australia, 1996. 
[11] J. N. Thorel, French Patent, 2723316, 1996.

[12] D. J. Brown and A. M. Dattner, "Phytotherapeutic approaches to common dermatologic conditions," Archives of Dermatology, vol. 134, no. 11, pp. 1401-1404, 1998.

[13] S. Chatterjee, R. N. Datta, D. Bhattacharyya, and Y. S. K. Bandopadhya, "Emollient and antipruritic effect of Itch cream in dermatological disorders: a randomized controlled trial," Research Letter, vol. 37, no. 4, pp. 253-254, 2005.

[14] C. Nam, S. Kim, Y. Sim, and I. Chang, "Anti-acne effects of oriental herb extracts: a novel screening method to select antiacne agents," Skin Pharmacology and Physiology, vol. 16, no. 2, pp. 84-90, 2003.

[15] Y.-W. Chin, H.-A. Jung, Y. Liu et al., "Anti-oxidant constituents of the roots and stolons of licorice (Glycyrrhiza glabra)," Journal of Agricultural and Food Chemistry, vol. 55, no. 12, pp. 46914697, 2007.

[16] N. Haleagrahara, J. Varkkey, and S. Chakravarthi, "Cardioprotective effects of glycyrrhizic acid against isoproterenol-induced myocardial ischemia in rats," International Journal of Molecular Sciences, vol. 12, no. 10, pp. 7100-7113, 2011.

[17] J. B. Vibha, K. Choudhary, M. Singh, M. S. Rathore, and N. S. Shekhawat, "A study on pharmacokinetics and therapeutic efficacy of Glycyrrhiza glabra: a miracle medicinal herb," Botany Research International, vol. 2, no. 3, pp. 157-163, 2009.

[18] B. Chowdhury, S. K. Bhattamisra, and M. C. Das, "Involvement of monoaminergic system in antidepressant- like activity of Glycyrrhiza glabra root extracts in rat," Pharmacologyonline, vol. 2, pp. 405-415, 2011.

[19] G. Yin, L. Cao, P. Xu, G. Jeney, M. Nakao, and C. Lu, "Hepatoprotective and antioxidant effects of Glycyrrhiza glabra extract against carbon tetrachloride $\left(\mathrm{CCl}_{4}\right)$-induced hepatocyte damage in common carp (Cyprinus carpio)," Fish Physiology and Biochemistry, vol. 37, no. 1, pp. 209-216, 2011.

[20] S. Asgary, N. Jafari Dinani, H. Madani, P. Mahzoni, and G. Naderi, "Effect of Glycyrrhiza glabra extract on aorta wall atherosclerotic lesion in hypercholesterolemic rabbits," Pakistan Journal of Nutrition, vol. 6, no. 4, pp. 313-317, 2007.

[21] N. Akhtar, S. H. M. Khan, A. Iqbal, B. A. Khan, and S. Bashir, "Glycyrrhiza glabra extract cream: effects on skin pigment 'Melanin,"' in Proceedings of the International Conference on Bioscience, Biochemistry and Bioinformatics (ICBBB '11), vol. 5, IPCBEE IACSIT Press, Singapore, February 2011.

[22] Y. Arase, K. Ikeda, N. Murashima et al., "The long term efficacy of glycyrrhizin in chronic hepatitis C patients," Cancer, vol. 79, no. 8, pp. 1494-1500, 1997.

[23] E. A. Davis and D. J. Morris, "Medicinal uses of licorice through the millennia: the good and plenty of it," Molecular and Cellular Endocrinology, vol. 78, no. 1-2, pp. 1-6, 1991.

[24] T. Takahara, A. Watanabe, and K. Shiraki, "Effects of glycyrrhizin on hepatitis B surface antigen: a biochemical and morphological study," Journal of Hepatology, vol. 21, no. 4, pp. 601-609, 1994.

[25] H. S. Ju, X. J. Li, B. L. Zhao, Z. W. Han, and W. J. Xin, "Effects of Glycyrrhiza flavonoid on lipid peroxidation and active oxygen radicals," Yao Xue Bao, vol. 24, pp. 807-812, 1989.

[26] A. Baran and H. Fenercioglu, "A research on the determination of properties and preservation of liquorice extract," Gida, vol. 16, pp. 391-396, 1991.

[27] M. K. Cook, "Makes natural sweeteners more versatile," Food Engineering, vol. 45, pp. 145-146, 1973.
[28] E. Dickinson, "Protein adsorption at liquid interfaces and the relationship to foam stability," in Foams: Physics, Chemistry and Structure, A. J. Wilson, Ed., pp. 39-54, Springer, London, UK, 1989.

[29] V. P. Arestov, "Method for production of sparkling wines," USSR Patent, 507640, 1976.

[30] B. V. Kafka, L. B. Sosnovskii, and O. A. Kharlamova, "Application of liquorice extract as foaming agent in halva production," Khlebopekarnaya Konditerskaya Promyshlennost, vol. 14, pp. 2122, 1970.

[31] N. N. Portnova, A. P. Khodak, T. N. Sukhikh et al., "Production of sweets with creme-type base," USSR Patent, SU1697688, 1991.

[32] M. Backleh-Sohrt, P. Ekici, G. Leupold, and H. Parlar, "Efficiency of foam fractionation for the enrichment of nonpolar compounds from aqueous extracts of plant materials," Journal of Natural Products, vol. 68, no. 9, pp. 1386-1389, 2005.

[33] M. Backleh, P. Ekici, G. Leupold, and H. Parlar, "Quantitative elimination of flavokavines A and B from Kava Kava (Piper methysticum G. Forst) by isoelectric focused adsorptive bubble separation," Naturwissenschaften, vol. 90, no. 8, pp. 366-369, 2003.

[34] M. Backleh, P. Ekici, G. Leupold, M. Coelhan, and H. Parlar, "Quantitative enrichment of ginger by isoelectric focused adsoptive bubble chromatography," Advances in Food Sciences, vol. 25, pp. 2-7, 2003.

[35] M. Backleh, G. Leupold, and H. Parlar, "Rapid quantitative enrichment of carnosic acid from rosemary (Rosmarinus officinalis L.) by isoelectric focused adsorptive bubble chromatography," Journal of Agricultural and Food Chemistry, vol. 51, no. 5, pp. 1297-1301, 2003.

[36] M. Backleh, P. Ekici, G. Leupold, M. Coelhan, and H. Parlar, "Enrichment of the glycoalkaloids $\alpha$-solanine and $\alpha$-chaconine from potato juice by adsorptive bubble separation using a $\mathrm{pH}$ gradient," Journal of Separation Science, vol. 27, no. 12, pp. 10421044, 2004.

[37] P. Ekici, M. Backleh-Sohrt, and H. Parlar, "High efficiency enrichment of total and single whey proteins by $\mathrm{pH}$ controlled foam fractionation," International Journal of Food Sciences and Nutrition, vol. 56, no. 3, pp. 223-229, 2005. 

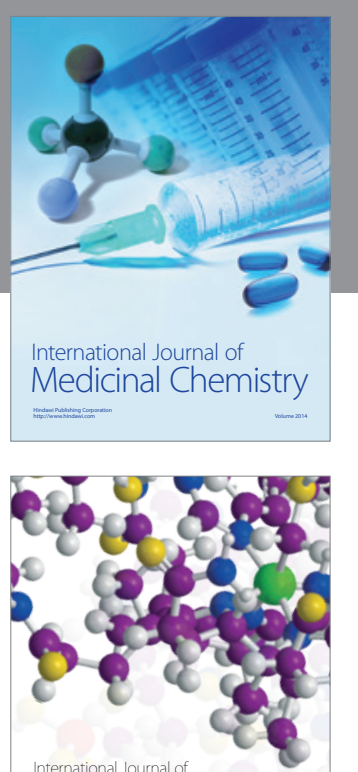

Carbohydrate Chemistry

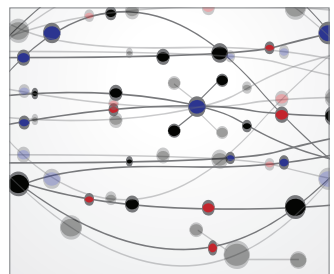

The Scientific World Journal
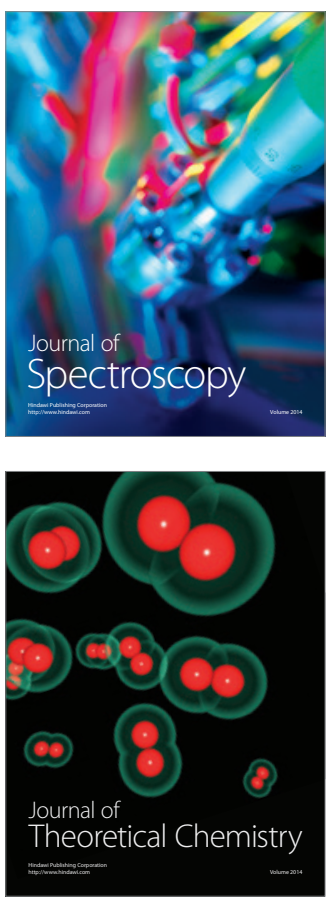
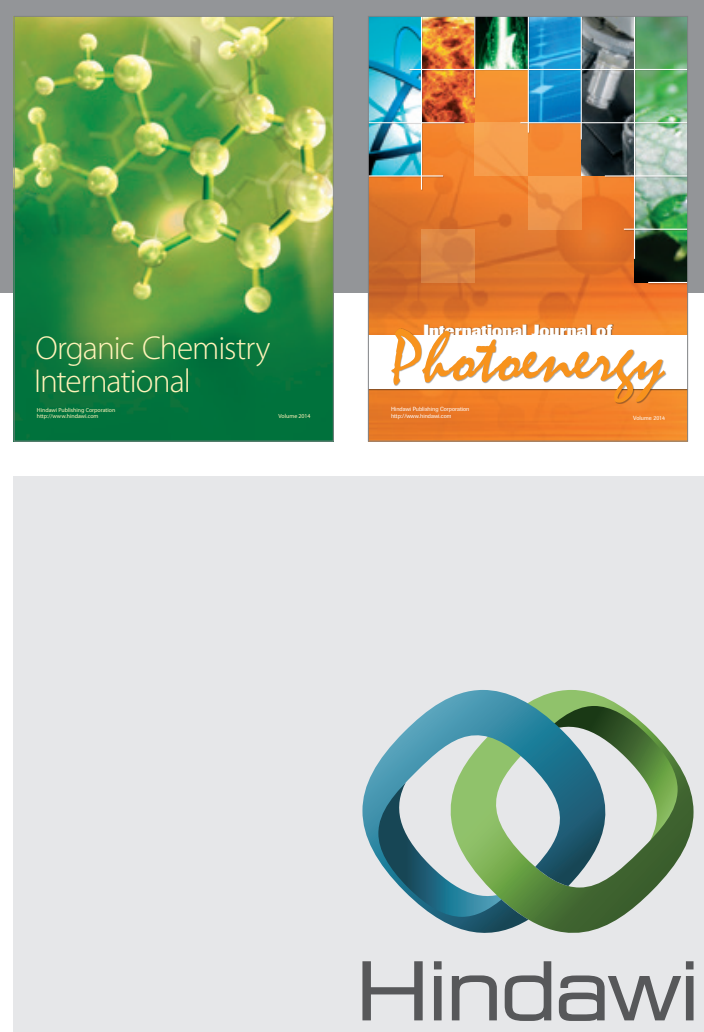

Submit your manuscripts at

http://www.hindawi.com

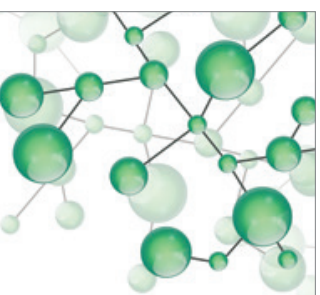

International Journal of

Inorganic Chemistry

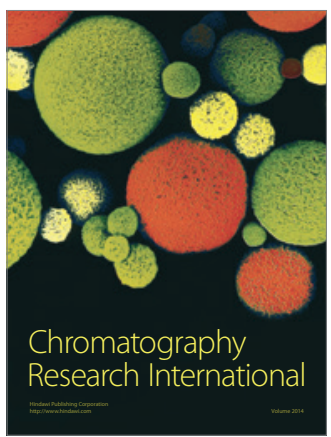

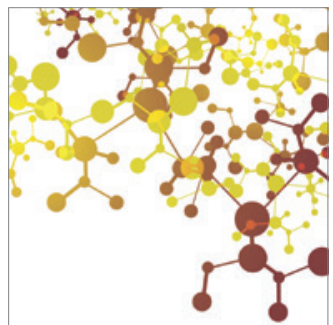

Applied Chemistry
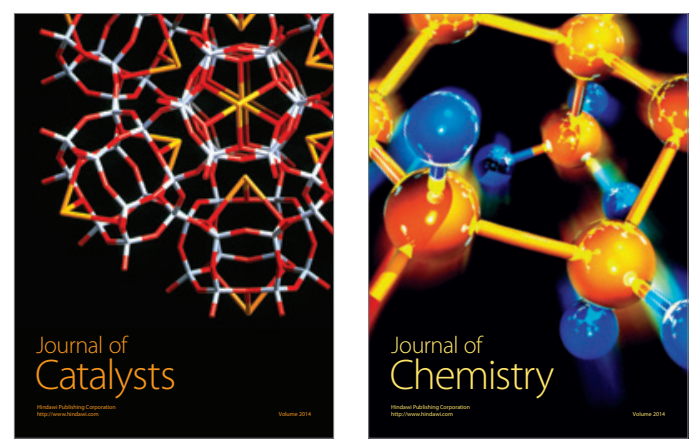
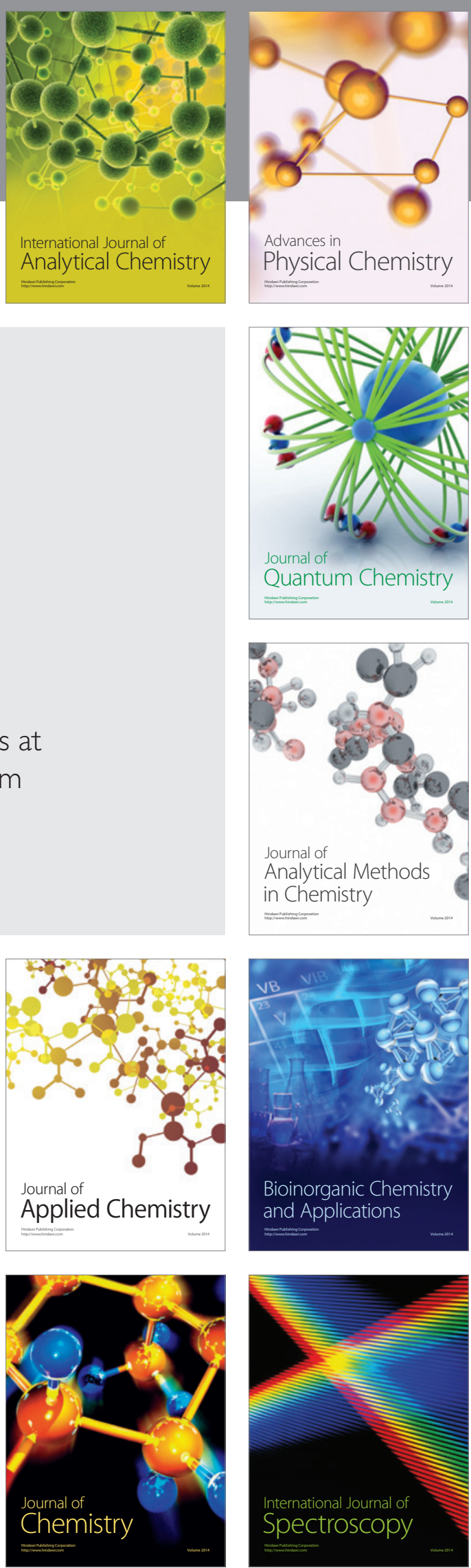